\title{
sciendo
}

DOI 10.2478/sbe-2020-0046

SBE no. 15(3) 2020

\section{THE TRIPLE LAYERED BUSINESS MODEL CANVAS MEETS THE BEEKEEPING SECTOR. GENERAL AND PARTICULAR CONSIDERATIONS FROM THE ROMANIAN INDUSTRY}

\author{
PANȚA NANCY DIANA \\ Lucian Blaga University of Sibiu, Romania
}

\begin{abstract}
:
Today, sustainability has been clearly recognized as a necessity at global level by many, and the role of the business environment as a contributor in ensuring sustainability has become more and more acknowledged lately. Several efforts undertaken in this direction were focused on obtaining higher life quality levels and long-term benefits through businesses' actions. Exploring and understanding agri-businesses from a managerial perspective becomes necessary due to sector's particularities, but also to the fact that they are generally small enterprises, deeply embedded into their local communities. Beekeeping, as an agricultural branch, has indispensable contributions at societal and environmental level through a number of activities related to food and medicinal product supply and pollination. Sector's dynamic, however, demonstrates that businesses are facing a series of challenges, and therefore, they need to showcase a proactive managerial approach in order to respond to risks and opportunities given by sustainability. Consequently, this paper looks to obtain a better understanding of sustainability management in the beekeeping sector by applying the triple layered business model canvas and featuring a series of facts from the Romanian industry.
\end{abstract}

Key words: Sustainable Development, Sustainability, Triple Layered Business Model Canvas, Beekeeping Sector

\section{Introduction}

Sustainable development and sustainability have become some of the greatest challenges of contemporaneity. Issues like climate change, poverty or resource overuse have become increasingly acknowledged by governments, organizations and general public. As a result, the pressure on businesses to integrate principles of sustainable development into their policies and activities has intensified. This has led to the exploitation of new sources of innovation in order to gain competitive advantage.

The concept of sustainable business has become increasingly widespread as organizations seek to adapt to a continuously changing environment and integrate environmental, social and economic aspects into their models. Thus, the need to innovate value-creating processes within business models has developed. Traditionally, innovation takes place by developing new products, services or processes, but more and more companies are now trying to innovate across the business model (Chesbrough et al., 
2013). Thus, business models constitute a means that can help organizations implement strategies appropriate to sustainable development (Schaltegger et al., 2015).

The interest for developing business model solutions in the agri-food sector has increased in recent years (Nosratabadi et al., 2019). Francheschelli et al. (2018) argue that sustainable business models innovation in the agri-food sector is particularly important due to the connection of the industry with nature and the human need for food, which is of strict necessity. The topic is also meaningful in the context in which many societal challenges are related to sustainable agriculture.

\section{Sustainable Business Model Aspects}

A business model is understood as a structured managerial tool that is essential to the success of an organization (Baden-Fuller and Morgan, 2010) and that is viewed as a general representation of the company (Amit and Zott, 2010). Current business models are often focused on creating, delivering and capturing economic value, regardless of social or ecological value (Evans et al., 2017). However, sustainable development is key for the long-term success of the organization, and thus business model innovation becomes mandatory for generating long-term sustainable value (Ludeke-Freund, 2010). Consequently, organizations that do not change their business models and adapt them accordingly to sustainable development will be more limited in gaining competitive advantage (Rana et al., 2017). Business model innovation can convey the incremental development of certain components of a strategy aimed at meeting the demand from a changing environment (De Reuver et al., 2009). On the other hand, business model innovation may refer to the overall reconfiguration of an existing model (Johnson et al., 2008).

According to Stubbs and Cocklin (2008), the conceptualization of a business model for sustainable businesses includes a mix of sustainable practices and seeks to create value for all stakeholders, both now and in the future. This can be achieved by minimizing environmental impacts, developing communities through business activities and creating economic value not only for shareholders but also for all stakeholders. In order to develop new business models that include sustainable development principles, businesses need to understand the tools available that enable the sustainable business modelling process. The Business Model Canvas is one of the most utilized tools for business models among practitioners. The instrument, proposed by Osterwalder and Pigneur (2010), is useful in providing an insight into the elements of the business model and into how they impact value creation (Joyce and Paquin, 2016).

The tool focuses mainly on the internal aspects of the organization, respectively on what it delivers and how it brings products and services on the market. Although the model helps firms in finding common ground between their goals and obtaining profit, practice has shown that social and environmental values are not highlighted due to the model's focus on creating economic value (Joyce and Paquin, 2016). Following the criticism, a number of sustainable business model tools, which integrate sustainable development principles have been developed. Among the most popular ones is the Triple Layered 
Business Model Canvas (Joyce and Paquin, 2016), which is also tackled in the present paper.

\section{Applying the Triple Layered Business Model Canvas in the Beekeeping Sector}

The Triple Layered Business Model Canvas (TLBMC) seeks to explore business model innovation by orienting models towards sustainable development and expanding the original canvas of Osterwalder and Pigneur (2010) by adding two new levels: the environmental level, which introduces the product life cycle perspective, and the social level, which builds on stakeholders' perspective (Joyce and Paquin, 2016). This approach allows structuring sustainability related aspects in terms of innovation and business model creation and adopts a triple bottom line approach. Therefore, the following section covers the way the triple layered business model canvas applies to the beekeeping sector, conveying a series of examples from the Romanian industry.

\subsection{Triple Layered Business Model Canvas. The Economic Layer}

The Business Model Canvas has in its structure nine components or building blocks, namely: customer segments, customer relations, channels, value proposition, cost structure, key activities, key resources, key partners and revenue streams, as proposed by Osterwalder and Pigneur (2010) and described below.

\subsubsection{Key Partners}

The component seeks to identify the main partners of an organization and for the beekeeping ones, the following partners were pointed out. Suppliers, which can be represented by local suppliers, but not only and can consist of (1) other apiaries for the production of biological material (eg. queens or bee families) and (2) legal entities producing equipment, respectively beekeeping accessories.

Purchasers and processors, which are the partners that ensure the collection and processing of honey and also fulfill the role of intermediaries, having the ability to facilitate the export of Romanian honey. According to Ministry of Agriculture and Rural Development' website, there are a number of 22 companies in Romania located in different parts of the country that are engaged in the acquisition and production of honey (MADR, 2020).

Landowners are partners who provide access to plants and can provide information on plant practices. Thus, beekeepers can opt for organic honey production by choosing the types of crops in which organic farming is practiced. This type of agriculture involves the non-use of genetically modified organisms, as well as their derivatives, synthetic fertilizers and pesticides, antibiotics, hormones and growth stimulants (European Commission, 2020). Although in Romania the practice of pollination contracts is not common, and beekeepers are not paid in exchange for pollination services, in the United States, beekeepers are paid by bee colony and the type of pollinated crop (Burgett et al., 2010). 
Other beekeepers can be considered partners as well, especially if the relationships created facilitate the exchange of knowledge and information.

Associative forms are a way for beekeepers to adhere to an environment related to their interests. The Association of Beekeepers provides its members access to a number of benefits such as obtaining materials needed for beekeeping (eg equipment, medicines, etc.), distributing bee products through the Association, providing technical and legal advice, and offering support for sanitary-veterinary assistance, practicing pastoral beekeeping or improving professional knowledge (Romanian Beekeepers Association, 2020).

Last but not least, the state can be considered a key partner, especially because of the funding programs provided in the sector. Examples from Romania include the National Beekeeping Program or the Minimis Aid to compensate for the effects of unfavourable hydrometeorological phenomena in the beekeeping sector (MADR, 2020).

\subsubsection{Key Resources}

Bees need diverse and abundant floral resources to stay healthy (Bradbear, 2004), which is why food resources are key. However, feeding bee colonies is a time-consuming task, and the beekeeper must ensure that it provides the necessary nutrients from carbohydrates and proteins (Sanford and Tew, 2004). In general, carbohydrates are provided by natural nectar (or sugar syrup), and most diets are concentrated on carbohydrates. Still, bees also need to be fed with proteins, which are found in pollen.

Beekeeping needs physical resources such as production equipment, protective equipment and infrastructure (transport, energy, construction). The hive is the most important beekeeping equipment, fulfilling roles such as providing shelter for bees or storing food reserves or harvesting, being necessary for the development of bees, as well as their transportation in the pastoral. Other resources include the equipment for handling bee families (eg. coveralls, gloves, smoker, etc.) and for extracting honey (eg. extractor) and processing it (eg. sweeper). In sustainable farms, the equipment is made locally, which contributes to the livelihood of people in the local community (Bradbear, 2004).

Financial resources are essential for the development of the apiary. Although at subsistence level they are not required to a large extent, they are needed in the sales and marketing process, depending on the capacity level of farm's processing and packaging. A sustainable bee farm will use its own financial resources and will not depend on external resources (Bradbear, 2004).

Last but not least, social resources such as professional networks can contribute to the development of the beekeeping sector. They can provide beekeepers with the means towards collective honey processing, as well as the access of products to markets. Also, being part of professional networks helps beekeepers create new contacts, identify new markets and improve their general understanding of the beekeeping sector (Bradbear, 2004).

\subsubsection{Key Activities}

Beekeeping is a practice that entails a series of knowledge and skills. The knowledge that beekeepers must have includes information on bee biology, bee equipment 
and products, the hive and its seasonal management, bee disease management, bee nutrition, and the harvesting of honey and other bee products. When beekeepers have information and technical skills, production can be considerably improved (Bradbear, 2004). Examples include improved honey harvesting and processing, and obtaining better prices by collecting or obtaining by-products. Also, management is important for obtaining an optimized bee production; the best manager is the one who will get as much output as possible from the bee colonies (Sanford and Tew, 2004). Thus, experience is particularly important, and knowing the characteristics of different bee types, as well as keeping a permanent and constant record are vital. Among the managerial problems in beekeeping are the control of the reproductive process of colonies, the change of the queen and the management of diseases.

A colony of honey bees is understood as an aggregate made of queen, drones, and several thousand worker bees living together, as a unit, in a hive. The beekeeper's operational activities include: inspecting colonies, feeding them, monitoring the growth and decline of the bee population, controlling the process of colony reproduction, harvesting bee products, preparing for winter and migrating towards improved nectar resources (Stanford and Tew, 2004). Because no year is identical to another in terms of meteorological phenomena, the beekeeper must closely monitor changes in the environment and anticipate potential effects on the colonies. Among the main challenges of beekeepers in the management of bee colonies are the process of breeding colonies, replacing the queen and treating bees in case of disease.

The management of bee colonies represents a considerable part of the beekeeper's time. However, it must also pay attention to other issues such as legislative changes in the field of beekeeping, either in order to comply with the requirements or to take advantage of the opportunities. In addition, participation in training courses (for the beekeeper in charge of the apiary or for the farm workers) is another activity that the beekeeper should take into account. Last but not least, although the marketing and sales of products are activities that the beekeeper should focus on closely, their related skills can often be poor.

\subsubsection{Value Proposition}

Beekeepers deliver the effort made on producing bee products. Bee products are used both as healthy alternatives in nutrition as well as products that have healing properties for various conditions. Beekeepers serve different customer segments, that look for different beekeeping products (from various types of honey, to pollen and royal jelly or other value-added products such as honey with sea buckthorn). The quality of bee products may vary in terms of content composition and may depend on the pollinated crops, which affect the possibility of obtaining various certifications (eg organic honey, honey eligible for export to the EU). In addition, beekeepers provide, by default, pollination services. 


\subsubsection{Channels}

The means of communication, promotion, sale and distribution of products help deliver value creation. They support customers in evaluating the value proposition of beekeeping businesses and increase awareness of product availability and quality.

The ways in which beekeepers reach customers vary, but direct channels are being favoured by small beekeeping entrepreneurs. The preference for direct channels over indirect ones is manifested mainly by customers (Tutuba et al., 2019), as products risk losing their freshness when stored for a long time on store shelves.

Farm gate selling in one of the main ways through which beekeepers ensure both direct selling of products (to locals and tourists, respectively) and wholesale to intermediaries, from which the products take the export route or end up being sold to domestic customers. Other channels include farmers markets, organized beekeeping fairs, and the online environment (own website, online social media platforms).

\subsubsection{Customer Segments}

Health and nutrition awareness as well as food quality issues have become salient for consumers in recent years. Thus, bee products are mainly sought after by individuals who look to obtain benefits from their consumption in various forms. Bee products are used by people of all ages, both in urban and rural areas. The urban honey market is segmented into individual households and the horeca industry, while at the farm gate the segmentation of customers involves consumers (locals or tourists) and wholesalers, respectively intermediary agents. Intermediaries are the link between bee products, in general, and sellers in the food, pharmaceutical or cosmetics industries, both on domestic and international markets.

\subsubsection{Customer Relationships}

Customer relationships establish the relationship between an entity that carries out economic activities in an ecosystem and its customer segments. The relationships established can range from interpersonal relationships to those facilitated by technological interfaces. In the beekeeping value chain, the actors involved frequently resort to social relations, and in rural areas these relations get even tighter. At local level, customers may often buy from people who have been recommended to them. If the beekeepers sell to end consumers, they become more concerned with strengthening social relationships and customer loyalty, as opposed to trading with intermediary buyers, where the beekeeper seeks to sell to those that offer the highest price.

\subsubsection{Cost Structure}

The cost structure describes the most important costs involved in operating a bee farm. Among the costlier resources are beekeeping equipment and utensils, which are fixed costs. However, the costlier activity is the management of the farm (Tutuba et al., 2019), which includes transport, labour costs, and bees' treatments. These are variable costs, which vary according to the farm's dimension. Other associated costs include taxes for utilizing the land for floral resources, taxes and fees paid to the state, utilities, sales and 
marketing costs, sanitary-veterinary analysis of products, or membership fee in associations etc.

\subsubsection{Revenue Streams}

The revenue streams component designates the value of revenue from each customer segment. The main way in which beekeepers earn income is by selling products obtained from exploiting bee families. Honey is the most popular bee product, and its aroma differs depending on the sources of nectar with which the bees are fed. Customers, especially end users, are willing to pay for quality honey, and therefore, traceability is a key aspect in the decision-making process related to the purchase (Tutuba et al., 2019). Intermediaries such processors aim to buy raw honey at a low price, as they have professional processing equipment.

Pollen, as a bee product, is the main source of protein for bees, being also a supplement used in diets. Its market value is higher as compared to honey, being available in smaller quantities. Propolis is a sticky substance derived from the secretion of various plants, being used in the pharmaceutical industry. Its market value is high due to high demand relative to supply. Also, beeswax is obtained along with honey, but it offers consistent income only when it is sold in bulk, in large quantities. It enjoys a high demand, especially in the cosmetics industry. Bee venom is a bee product that has uses in various forms of medical treatment, being also a product rarely extracted compared to other bee products, which benefits from a high market value. Regarding the payment preference, most merchants prefer cash payment (Tutuba et al., 2019). In addition, although monetizing pollination services is particularly common in the United States (Topitzhofer et al., 2020), in Romania this practice is rare, and beekeepers focus on the extraction of bee products.

\subsection{The Triple Layered Business Model Canvas. The Social Layer}

The triple layered Canvas model proposes a holistic approach, involving all stakeholders. The social level of the model seeks to encompass the social impact of the organization, and through it to identify the sources that produce the impact. Its nine components for the beekeeping sector have been described below.

\subsubsection{Local Communities}

Social relationships are built primarily with the local community, and the success of an organization often depends on how these relationships are developed and maintained. From the beekeeping activity, we may note in this regard providing (1) direct benefits for the local community (eg. production of honey and other bee products) and (2) indirect benefits (eg. plant pollination, slowing down urbanization, slowing down deforestation). In general, the main location of beekeeping activities is a fixed one, usually situated in rural areas. However, in order to ensure sufficient (quality) food resources for bees, it can often happen for the system used to be one based on mobility, respectively on pastoral beekeeping. This determines the creation and maintenance of relationships with people located in pastoral areas. 


\subsubsection{Governance}

The governance component includes the organizational structure and decisionmaking policies of an organization. It establishes with whom and how the organization will develop relationships (Joyce and Paquin, 2016). The internal structure concerns the organizational hierarchy, and in the case of beekeeping farms this is a simple one, which does not involve complexity, as the beekeeper is often the only worker who handles all the activities and operations necessary for running the apiary. If there are several workers in the beekeeping farm, the owner is the one in charge with carrying out most of the activities (from the execution ones, up to the administrative ones). More, the farmer who also owns the apiary is often the mostly specialized from the farm site regarding beekeeping practices. With concern to decision-making policies, they include the non-financial criteria pursued by the farmer, the distribution of profits or the measures taken in relation to workers' behaviour.

\subsubsection{Employees}

The employee component recognizes workers as the main stakeholders in an organization (Joyce and Paquin, 2016). It refers to a series of elements such as the number of employees, or their characteristics that vary from quality of life to aspects related to human development. These include wage differences, ethnicity, educational level, financial well-being, professional development opportunities, etc. At apiary level, the number of people working in it is small, and business is usually carried out at family level, even in the case of professional farms, which have a high number of bee colonies. This can be attributed to the seasonality of the sector (which is why the beekeeping manager can use day laborers) or to the level of qualification (since those who have knowledge in the field are those who operate on their own business). Thus, the analysis of the characteristics of the employees of the beekeeping can made in order to have a global image of the component in dynamics, from one year to another.

\subsubsection{Social Value}

This component addresses aspects of organization's mission that deal with creating benefits for stakeholders and society (Joyce and Paquin, 2016). In the beekeeping sector, the recognition of bees in terms of pollination is unanimous nowadays, especially since over $90 \%$ of the top 107 agricultural crops worldwide are obtained with the help of bees (Klein et al., 2007). A less explored area of pollination tackles its contribution to biofuels; also, some crops offer higher yields when pollinated by bees (Perrot et al., 2018). More, beekeeping organizations contribute to improving the quality of life of consumers by offering healthy and tasty products; bee products provide nutritional values rich in nutrients, antioxidants, vitamins and minerals (Kocot et al., 2018). Also, bee products provide medicinal value, being used not only in traditional medicine, but also in modern medicine (Kocot et al., 2018).

\subsubsection{Societal Culture}

This component recognizes society as a whole in relation to the organization, together with the potential impact that organizations have on society (Joyce and Paquin, 
2016). In addition, it includes how organizational actions can have a positive influence on society (Steurer et al., 2005). In the beekeeping sector, we may observe a culture of entrepreneurial opportunities that develops in the rural climate, as well as a culture of women's empowerment in this regard (Pocol and McDonough, 2015). More, the provenance and authenticity of the products can also help creating a culture that supports the consumption of local products. Last but not least, bee products can develop a culture of a healthy diet, taking it even further than it currently is.

\subsubsection{Scale of Outreach}

The scale of outreach encompasses the degree of depth and breadth of the relationships that an organization creates with its stakeholders over time. The component is based on the development of integrative and lasting relationships, but also on the extended impact at geographical level, from the local scale to the regional and global scale (Joyce and Paquin, 2016). In Romania, local honey does not have a substantial presence on hypermarkets shelves due to dumping prices of honey imports, as well as high commissions for Romanian beekeepers (Digi24, 2019). In addition, there is a low honey consumption level per capita in Romania, of roughly 1 kilogram / year (Panța, 2018), as well as a high demand for honey on external markets due to its high quality, which contributes to the export of products. More, the global economy, but also the trade agreements facilitated by the European Union (EU) between its Member States made Romania a net exporter of honey, with approximately 10,000 tons exported annually (Panța, 2018). The main countries to which Romanian honey is delivered are Germany (main partner for export), Italy, France, Spain, Great Britain or Belgium (Panța, 2018). Outside the EU, Romanian honey reaches countries such as Japan, Israel or China. However, export conditions are strict, and the exported honey is subjected to a complex set of analyses which are not applied to any other food product on the European market (Digi24, 2019).

\subsubsection{End-User}

This component targets the person who benefits from the value proposition, and aims to discover how the value proposition responds to consumer's needs (Joyce and Paquin, 2016). The final consumer of bee products can be classified into multiple categories, depending on the product and use (food, cosmetic, medicinal). In general, the demographic characteristics of consumers can vary depending on age, income level, educational level, and more. In the case of honey, the most popular bee product, the final consumers do not vary according to age, but honey is more popular among people who are more conscious in terms of a healthy diet. Thus, honey producers seek to provide value by meeting consumers' expectations in terms of taste, texture, but also quality (eg. unprocessed honey, obtained from bees that feed on organic crops, etc.). Regarding bee products for medicinal or cosmetic use, these are generally consumed by people over 18 years old, who want to optimize a certain state or treat a certain condition. Thus, the value expected by them consists in the intake of ingredients and vitamins (from products such as royal jelly, propolis, etc.). 


\subsubsection{Social Impact}

The social impact component includes the cost created by an organization at societal level (Joyce and Paquin, 2016) and it complements and extends the financial costs of the economic level. Although social measures have gained consistency in recent years, there is still no consensus on what to measure and how. In any case, the indicators are often tailored to each organization. In the beekeeping sector, businesses have a low negative social impact, given only by potential bee stings and allergies.

\subsubsection{Social Benefits}

The social benefits address organizations on creating positive social value through their actions (Joyce and Paquin, 2016). Like social costs, social benefits can be quantified through various indicators. At beekeeping business level, one of the widespread social benefits is the well-being of consumers (Gill et al., 2016), while maintaining planetary life support systems. Moreover, beekeeping businesses ensure, through their activity, food security. Another benefit is the one that supports and develops the livelihood of rural individuals involved in beekeeping, by ensuring a sustained income level. Last but not least, elements of beekeeping (eg. honeycomb) have become a source of inspiration for fields such as engineering or architecture (Zhang et al., 2015).

\subsection{The Triple Layered Business Model Canvas. The Environmental Layer}

The environmental layer is used to have a clearer picture of how organizations generate ecological benefits to cover the caused ecological impact. This enables identifying the most significant environmental impacts and draws attention to those aspects that an organization should take into account when aiming to create environmentally oriented innovation.

\subsubsection{Functional Value}

Functional value is a component that reflects the results of an organization's service or product through a quantitative description of the satisfied needs, beginning with the functional unit in the product life cycle evaluation (Joyce and Paquin, 2016). In the beekeeping sector, the functional unit in the evaluation of the life cycle of honey would be the consumption of 3 grams of honey in the case of Romanian consumers (Panța, 2018), while the functional value would be given by all the units consumed by individuals in a certain time period (approximately 1 kilogram of honey / year).

\subsubsection{Materials}

This component represents the ecological extension of key resources from the original model and refers to the bio-physical elements used by the organization to create functional value (Joyce and Paquin, 2016). If the elements are generally comprehensive and varied, the model should include only the main ones in relation to the ecological impact that is being caused. In the beekeeping sector, businesses have a low overall ecological impact, especially in terms of used materials. However, the main materials include product packaging containers (usually made of glass or plastic), automobiles (fuel consuming) used for pastoral beekeeping, distribution and supply, and processing 
equipment (electricity consuming). The infrastructure used in beekeeping, though hives, can not be considered a main element in the component, due to the fact that they are generally made of renewable materials (eg. wood).

\subsubsection{Production}

The production component is an extension of the "key activities" component from the original model and refers to the actions that an organization undertakes in order to create value (Joyce and Paquin, 2016). As in the case of materials, only the main activities are considered, namely those that have a considerable ecological impact. For the beekeeping business, the activities that can be considered include transportation (for transhumance, supply and distribution) that produces carbon emissions, but also those of processing bee products, which involve electricity consumption. However, in general, beekeeping activities have a low environmental impact.

\subsubsection{Supplies and Outsourcing}

This component includes those materials and production activities that are necessary for functional value, but which are not fundamental to the organization (Joyce and Paquin, 2016). In beekeeping businesses, these aspects encompass water or electricity consumption, which can be provided by utility companies. However, beekeepers can gain a greater degree of control over these resources by creating renewable energy sources on farm site (eg. solar energy).

\subsubsection{Distribution}

Distribution involves the transport of goods which ease the access to functional value (Joyce and Paquin, 2016). At ecological level, distribution is analysed through the means of transportation, the distances travelled or the weight of the transported goods. For beekeeping businesses, the distribution of the main bee product, honey, is achieved through the transport of the packaged goods in disposable packaging (intended for use in the horeca industry), jars (for retail) or barrels (for wholesale). Distances vary by destination (local fairs, hypermarkets, or overseas warehouses in case of export).

\subsubsection{Use Phase}

This component tackles the impact of the way the consumer takes part in the functional value of a product or service (Joyce and Paquin, 2016) and includes the consumption of resources that occurs during usage (eg. household appliances, through energy consumption during functioning). In the case of bee products, this component has a low impact as we may only consider the water consumption needed to clean the honey storage containers for reuse or recycling.

\subsubsection{End-of-Life}

The end-of-life of the product component refers to the moment when the consumer ends the use of the functional value (Joyce and Paquin, 2016). This involves aspects of reusing product's materials (through refabrication, recycling, disassembling or identifying new utilities) or disposing them (through incineration or landfill elimination). The component 
encourages organizations to find new ways of managing their impact by extending accountability beyond the value of its products. For beekeeping businesses, this means considering the impacts of packaging (mainly glass, plastic or cardboard) of the products consumed. Generally, packaging follows different paths and can end up being reused, recycled or disposed to the landfill.

\subsubsection{Environmental Impacts}

This component includes the environmental costs of the organization's actions and may incorporate measurements such as carbon emissions, impact on ecosystem, human health, natural resources depletion, or water consumption (Jolliet et al., 2003). For beekeeping businesses, the most significant ecological costs produced include the ones caused by product distribution, that involves carbon emissions, but also the ones caused by the end of product's life cycle, through the impact upon the ecosystem in terms of resources consumed for packaging.

\subsubsection{Environmental Benefits}

Last but not least, the environmental benefits component extends the concept of value creation beyond financial considerations (Joyce and Paquin, 2016). Thus, it addresses the ecological value created by the organization in terms of reducing negative ecological impacts and creating positive ecological value. This way, the component encourages innovation at organizational level. As for beekeeping businesses, these create ecological value by default through the pollination process. In addition, studies show that the yield of fruits and vegetables resulted from bee pollinated crops has a higher quality, as well as a longer shelf life (Klatt et al., 2014). Again, a less explored area related to pollination is given by its contribution to biofuels (Perrot et al., 2018). Also, ecological value can be obtained by identifying and implementing alternatives to those aspects that produce negative ecological impact. Such examples include the use of biodegradable and compostable packaging materials, and the use of low-emission means of transport, or electric vehicles, respectively.

\section{Conclusion}

The TLBMC model highlights the intangible links both within the organization and between the organization and the external environment. It can be used as a tool for creating business models through which the business model is visualized in terms of the aggregate impacts of the business at all three levels. Also, it can be used to level the costs and benefits of the business by applying the triple bottom line perspective.

These are applicable to enterprises in the beekeeping sector. However, a good business model must aim at creating value for customers, as well as retaining value for participants in the ecosystem. Addressing partners in business models can support this, and can also stimulate the improvement of the company's capabilities and resources. Even though beekeeping enterprises are sustainable by default in a series of aspects (many social and environmental benefits covering the few social and environmental impacts), they 
could pay attention to its deficiencies in relation to sustainability and find ways to adapt accordingly.

\section{References}

Amit, R., Zott, C., (2010), Business model innovation: Creating value in times of change, IESE Business School Working Paper No. 870. http://dx.doi.org/10.2139/ssrn.1701660

Baden-Fuller, C., Morgan, M.S., (2010), Business Models as Models, Long Range Planning, Vol. 43, pp. 156-171.

Bradbear, N., (2004), Beekeeping and Sustainable Livelihoods, Agricultural Support Systems Division, Food and Agriculture Organization of the United Nations, available at http://www.fao.org/3/y5110e/y5110e00.htm

Burgett, M., Daberkow, S., Randal R.., Thurman, Walter., (2010), US Pollination Markets: Recent Changes and Historical Perspective, American Bee Journal, Vol. 150, No. 1, pp. 35-41

Chesbrough, H., Di Minin, A., Piccaluga, A., (2013), Business model innovation paths. In: Cinquini L., Minin A.D., Varaldo R. (eds) New Business Models and Value Creation: A Service Science Perspective, Springer for innovation, Vol. 8, pp. 45-66.

De Reuver, M., Bouwman, H., Maclnnes, I., (2009), Business model dynamics: A case survey, Journal of theoretical and applied electronic commerce research, Vol. 4, No. 1, pp. 1-11.

Digi 24 News Journal, (2019), available at https://www.digi24.ro/stiri/actualitate/social/presedinteleaca-avem-probleme-cu-vanzarea-mierii-in-supermarket-sunt-costuri-extraordinare-1106575

European Commission, (2020), available at https://ec.europa.eu/info/food-farmingfisheries/farming/organic-farming/organic-production-and-products_ro

Evans, S., Vladimirova, D., Holgado, M., Van Fossen, K., Yang, M., Silva, E., Barlow, C., (2017), Business Model Innovation for Sustainability: Towards a Unified Perspective for Creation of Sustainable Business Models, Business Strategy and the Environment, Vol. 26, pp. 597-608.

Franceschelli, M.V., Santoro, G. and Candelo, E., (2018), Business model innovation for sustainability: a food start-up case study, British Food Journal, Vol. 120, No. 10, pp. 24832494.

Gill, R.J., K.C.R. Baldock, M.J.F. Brown, J.E. Cresswell, L.V. Dicks, M.T. Fountain, M.P.D. Garratt, L.A. Gough., (2016), Protecting an ecosystem service: Approaches to understanding and mitigating threats to wild insect pollinators. In Ecosystem services: From biodiversity to society, Part 2, vol. 54, ed. G. Woodward and D.A. Bohan, 135-206., Academic Press London: Advances in Ecological Research.

Jolliet, O., Margni, M., Charles, R., Humbert, S., Payet, J., Rebitzer, G., Rosenbaum, R., (2003), IMPACT 2002+: A new life cycle impact assessment methodology, Int J LCA, Vol. 8, pp. 324

Johnson, M. W., Christensen, C. M., Kagermann, H., (2008), Reinventing Your Business Model, available at $\mathrm{https}: / / \mathrm{hbr}$.org/2008/12/reinventing-your-business-model

Joyce, A., Paquin, R., (2016), The triple layered business model canvas: A tool to design more sustainable business models, Journal of cleaner production, Vol. 135, pp. 13-1486.

Klatt, B.K., A. Holzschuh, C. Westphal, Y. Clough, I. Smit, E. Pawelzik, T. Tscharntke., (2014), Bee pollination improves crop quality, shelf life and commercial value, Proceedings of the Royal Society B 281: 20132440.

Kocot, J., M. Kiełczykowska, D. Luchowska-Kocot, J. Kurzepa, I. Musik., 2018, Antioxidant potential of propolis, bee pollen, and royal jelly: Possible medical application, Oxidative Medicine and Cellular Longevity, available at https://www.hindawi.com/journals/omcl/2018/7074209/

Lüdeke-Freund, F., (2010), Towards a Conceptual Framework of Business Models for Sustainability, Social Science Research Network, available at https://papers.ssrn.com/abstract=2189922 
Ministry of Agriculture and Rural Development, (2020), available at https://www.madr.ro/programulnational-apicol/lista-forme-asociative/societati-comerciale.html

Nosratabadi, S., Mosavi, A., Shamshirband, S., Kazimieras Zavadskas, E., Rakotonirainy, A., Chau, K. W., (2019), Sustainable business models: A review, Sustainability, Vol. 11, No. 6.

Osterwalder, A., Pigneur, Y. (2010): Business Model Generation: A Handbook for Visionaries, Game Changers, and Challengers, Wiley, New Jersey.

Panța, N., (2018), Honey Market Dynamics. The Case of Romania, Management of Sustainable Development, Sciendo, Vol. 10, No. 2, pp. 13-16.

Perrot, T., S. Gaba, M. Roncoroni, J.-L. Gautier, V. Bretagnolle., 2018, Bees increase oilseed rape yield under real field conditions, Agriculture, Ecosystems \& Environment, Vol. 266, pp. 39-48.

Pocol, C.B., M. McDonough., (2015), Women, apiculture and development: Evaluating the impact of a beekeeping project on rural women's livelihoods, Bulletin of University of Agricultural Sciences and Veterinary Medicine Cluj-Napoca, Horticulture, Vol. 72, pp. 487-492.

Rana P., Short S.W., Evans S., Granados M.H., (2017), Sustainable Business Models: Theoretical Reflections. In: Liyanage J., Uusitalo T. (eds) Value Networks in Manufacturing. Springer Series in Advanced Manufacturing. Springer, pp. 95-109

Romanian Beekeeepers Association, (2020), available at www.aca.org

Schaltegger, S., Hansen, E., Ludeke-Freund, F., (2015), Business Models for Sustainbility: Origins, Present Research, and Future Avenues, Organization \& Environment, Vol. 29, no. 1, pp. 310.

Sanford, M. T., Tew, J. E., (2005), Apiculture (Beekeeping), In Encyclopedia of Entomology, Springer Netherlands, pp. 147-158, available at https://doi.org/10.1007/0-306-48380-7_258

Steurer, R., Langer, M.E., Konrad, A., Martinuzzi, A., (2005), Corporations, Stakeholders and Sustainable Development I: A Theoretical Exploration of Business-Society Relations, J. Bus. Ethics, Vol. 61, pp. 263-281.

Stubbs, W., Cocklin, C., (2008), Conceptualizing a "Sustainability Business Model", Organization \& Environment, available at https://doi.org/10.1177/1086026608318042

Topitzhofer, E., Breece, C., Wyns, D., Sagili, R., (2020), Revenue Sources for a Commercial Beekeeping Operation in the Pacific Northwest. Pacific Northwest Extension Publishing.

Tutuba, N. B., Tundui, H. P., Msamula, J. S., (2019), Value Creation and Value Appropriation: A Business Model Encompassing the Beekeeping Industry in Tanzania, Proceedings of the European Academy of Management (EURAM 2019) conference, Lisbon, Portugal, $26-28$ June 2019, ISSN 2466-7498.

Zhang, Q., X. Yang, P. Li, G. Huang, S. Feng, C. Shen, B. Han, X. Zhang., (2015), Bioinspired engineering of honeycomb structure-Using nature to inspire human innovation, Progress in Materials Science, Vol. 74, pp. 332-400. 